\title{
Dermal sense organs and their significance in the feeding behaviour of the common sole Solea vulgaris*
}

\author{
S. Appelbaum and Ch. Schemmel
}

Zoologisches Institut und Museum der Universität Hamburg, Martin-Luther-King-Platz 3, D-2000 Hamburg 13, Federal Republic of Germany

\begin{abstract}
Light and electron microscopic studies on dermal sense organs of the sole Solea vulgaris Quensel, 1806 reveal that the sensory buds - located in large numbers between the papillae, mainly on the abocular side of the fish - are certainly free neuromasts. It is suggested that these papillae serve as protectors for the sensitive neuromasts rather than as sensory organs. They may improve the perception function of the neuromasts for mechanical stimuli. Taste buds, in different distributions, were found only in oral cavity, pharynx on gill rakers, and on lips. The lateral line system, though partly asymmetrical, is highly developed on both the ocular and abocular sides of the fish. The nasal sac of the abocular side is smaller in size and contains fewer lamellae than that of the ocular side of the fish. Ocular and abocular nasal sacs are connected via an accessory sac. Results indicate the significance of mechanoreceptors for the feeding behaviour of post-metamorphosed sole which are known to feed most actively at night and until now have been thought to detect food primarily by means of chemoreception.
\end{abstract}

\section{INTRODUCTION}

The sensory organs of the sole were first described in the last century (Raffaele, 1886; Cunningham, 1890). Tirelli $(1936,1938)$ investigated the morphology and anatomy of the papilla and its surrounding sensory buds on the abocular side and related the arrangement of the papillae structure to the taxonomy of the sole genus.

Investigations into the olfactory organs of the sole had likewise been carried out by Bateson as early as 1890 and by Burne (1909) classifying them as highly developed. Evans (1937) ascertained that in the central nervous system of Solea solea greater importance is to be ascribed to the olfactory rather than the optical centre.

Moreover, the sole was recognised early as a nocturnal fish' (Heape, 1887; Cunningham, 1890; Butler, 1895). This was confirmed later by examinations of the

\footnotetext{
- The representations regarding neuromasts in sole in Appelbaum et al. (1983) are based on discussions and studies with C. Schemmel. In the present study, author names are in alphabetic order
}

clearly differentiated sensory organs (de Groot, 1969; Holl, 1965). Reports on the link between sensory organs and behaviour of feeding sole have been written by Chabanaud (1927), de Groot and Corten (1967) Mackie et al. (1980), and Appelbaum et al. (1983). In general, chemoreception is regarded as the main mechanism in sole feeding behaviour. The sensitivity of sole to chemical stimuli has been thoroughly investigated as far as its significance for feeding pattern is concerned (Mackie et al., 1980, 1982).

In the last decade the sole has attracted much interest, not least because of its economic significance. Thus there have been several attempts to breed sole under controlled conditions (Kirk, 1973; Shelbourne, 1975; Girin, 1977; Bromley, 1977). Findings on the behaviour of young sole have contributed to these experiments (Flüchter, 1966; Rosenthal, 1966).

The present authors have investigated more closely the dermal sensory organs of the sole, including the olfactory organs. Particular attention has been focussed on the mechanoreceptors which have previously not been recognised as such. Their importance for food intake may contribute to the development of appropriate culture techniques. 


\section{MATERIALS AND METHODS}

Solea vulgaris were collected in the German Bight and the southern part of the North Sea during research cruise numbers 105 (January 1981), 109 (May 1981), and 112 (October 1981) on board FFS 'Anton Dohrn'. Adults, juveniles and larvae were examined. For comparison, a number of plaice (Pleuronectes platessa), dab (Limanda limanda), and solenette (Buglossidium luteum) were also collected and studied.

For observation and description of the external morphology of sensory buds and papillae, $5 \%$ chromic acid and $4 \%$ formalin were applied (Schemmel, 1974). This treatment yielded a particularly clear picture of the surface structures, causing slight variations in the contractions of epithelial areas. Neuromasts were observed in living fish by tissue staining. After anaesthetization with MS 222, fish were transferred to a glass dish containing freshwater. A strongly concentrated solution of methylene blue was injected directly, on the surface of a particular epidermis region (under water) by means of a thin glass pipette. In this way the neuromasts, together with the cupula, were stained dark blue and became clearly visible.

Histological examinations were made by light and electron microscopy. A series of cross-sections from the head region of adult fish (11 and $15 \mathrm{~cm}$ in length) and of larvae were prepared. Heads of adult fish were decalcified with trichloracetic acid and embedded in paraplast. The sections were stained according to the Pasini staining method (Romeis, 1968). Electron microscopy was performed with a Zeiss EM 9S-2. For scanning examination a stereoscan S4 Cambridge Scientific Instrument was used.

Samples were fixed in $4 \%$ glutaraldehyde in a phosphate buffer; second fixing in $2 \%$ osmiumtetraoxide; embedding in Spurr. Semithin sections (ca. $1 \mu \mathrm{m}$ ) were stained in $1 \%$ toluidine blue/pyronin $(4: 1)$ in $1 \%$ borax for 1 to $2 \mathrm{~min}$ at $60^{\circ} \mathrm{C}$. Ultrathin sections (ca. 500 to $700 \mathrm{~A}^{\circ}$ ) were contrasted on copper plates in uranylacetate/lead citrate. For scanning observation, tissues were dehydrated in graded alcohols, critical pointdried and sputter-coated with gold. Small living sole were fed with Artemia nauplii and observed over a long period of time.

\section{RESULTS}

\section{Mechanical sense organs}

Lateral line canal

The lateral line is a highly developed mechanoreceptor organ system found in all lower aquatic vertebrates. In fish it consists of long rows of sense organs which are either buried in canals or lie free in the epidermis. The canal system of the sole shows signs of secondary modifications particularly in the head which are related to metamorphosis. As on the abocular side, the trunk canal on the ocular side is well developed and without fragmentation for its whole length up to the tail fin. Between each 2 pores lies a canal organ. In the front region, particularly in the adult, there are multiple small canal openings so that groups of 2 to 3 small pores lie close to one another. The number of neuromasts in the trunk canal is ca. 135, and to a great extent independent of length (e.g. fish total length $(\mathrm{TL})=6 \mathrm{~cm}: 130-135, \mathrm{TL}=$ $21 \mathrm{~cm}: 137-140$ ). The trunk canal emerges ontogenetically after the formation of the canals in the head region.

The canal system in the head region, the number of canal organs and the homology with the normal head canal system of a bilaterally symmetrical fish are shown in Fig. 1. During metamorphosis, shifting of the left eye to the right side influences above all the arrangement of orbital canals. The forward change of position of the dorsal fin to nearly the tip of the snout also changes the formation of the occipital canal. The preopercular-mandibular canal (POC-MBC) remains almost unimpaired by metamorphosis. It extends on the ocular side with 8 pores (or rather groups of pores) and 7 canal organs in a large curve up to the tip of the snout. On the abocular side the canal is short around the mandibular section and contains 5 canal organs with 5 pores (or rather groups of pores). The infraorbital canal is totally reduced and the supraorbital canal undergoes considerable displacement ${ }_{i}$ ontogenetically, it is positioned previously as the first canal and even before metamorphosis is formed bilaterally symmetric as the mandibular canal. The left-hand supraorbital canal (SOC) thereby moves deep into the inner head region through a shift of the eye and develops a direct proximity to the right-hand SOC. Only in the foremost rostral area does the left/right symmetry remain, in that each SOC which starts in front of a nasal inlet contains a sense organ, branching off in a dorsal direction and extending backwards over the nose. In the rear, both SOCs are joined together by a frontal commissure (FC) without neuromasts that lies deep inside the head. Behind it, the left SOC climbs up to the surface of the head and ends with the temporal canal (TC). Conspicuously, in spite of the modification of both SOCs and TCs, each side retained the same number of neuromasts and pores $(7$ canal organs, 6 pores up until the branching off of the occipital canal [OC]). The OC branches off at the point where the trunk canal joins without a curve, with circumvention of the pectoral fin (in contrast to Pleuronectes platessa and Limanda limanda), to the TC. Both sides of the OC 
Fig. 1. Solea vulgaris. (A) Lateralline system of head, drawn according to serial sections. Black dots: canal neuromasts. (B) Diagrammatic presentation of head lateral line system. FC: frontal commissure; $\mathrm{MBC}$ : mandibular canal; OC: occipital canal; POC: preopercular canal; SOC: supraorbital canal; TC: temporal canal; TLL: trunk lateral line; dotted lines: secondary canals. (C) Grape-like tubules resulting from multiplication of a canal pore

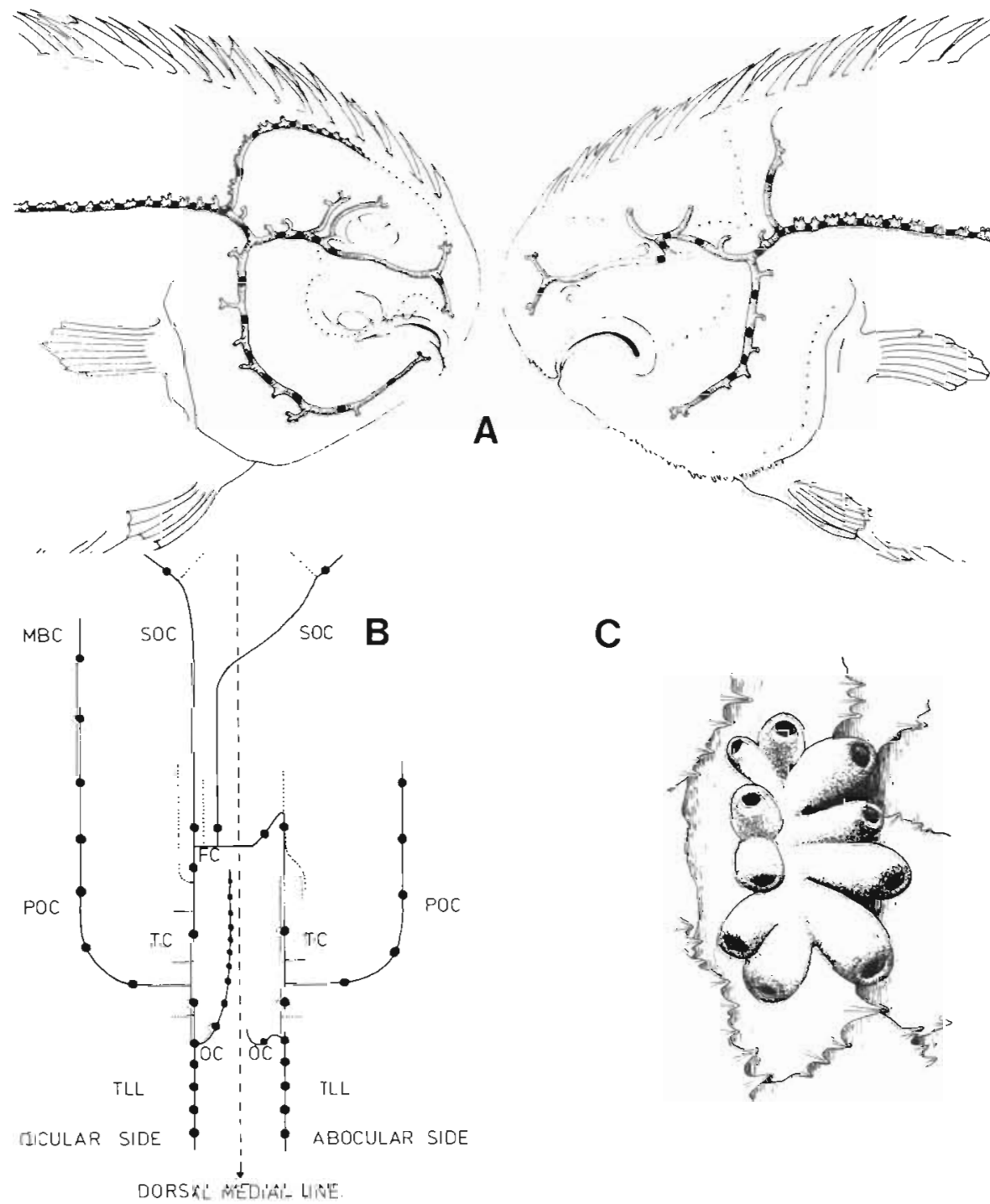

are very different in their course. On the abocular side the OC contains only 2 to 3 sense organs and is short and interrupted. On the ocular side it extends in a broad curve to the tip of the snout, clearly distinguishable with many neuromasts (at least 10 ). The dorsal fin, drawn to the front of the fish, interrupts the connection of the canal on both sides, whereby the right-hand OC has obviously been carried by the proportional shift in the head region. In this way, a new secondary symmetry of the canal system emerges on the ocular side (Fig. 1 A), a symmetry which could be important for the location of adequate stimuli in open water. All further canals, in particular the ones simulating an infraorbital canal over the left eye, are short tubules without canal organs which branch off the main canal.

The canal pores are very narrow in the sole and are only simple in small fish until shortly after metamorphosis. As a result of the multiplication of pores and their extension to the tip of the many small tubules, grape-like structures emerge, particularly in the head region in place of a larger, more simple canal opening (Fig. 1C). They keep the canal system functional (i.e. open to water) and protect it from penetrating particles.

\section{Free neuromasts}

Free neuromasts, which occur singly and are generally round, are found in high but varied concentrations on the abocular side of the head. They extend from the tip of the head to just inside the scaly region and sometimes to the rear section of the operculum. The highest concentration of neuromasts occurs around the anterior naris. Between here and the mouth the number of neuromasts in a fish about $8 \mathrm{~cm}$ long is ca. $10 \mathrm{~mm}^{-2}$. Further away from nose and mouth the 
density decreases. In less dense regions the number of neuromasts is about $5 \mathrm{~mm}^{-2}$ or less. The total number of neuromasts in the head area of an $8 \mathrm{~cm}$ long sole is estimated to be 400 to 500 .

At first glance the appearance of free neuromasts is quite astonishing, as one would expect the sensitive cupula on the abocular side of a benthic fish to be easily damaged by substrate exposure. It is probably for this reason that the neuromasts in the sole have been incorrectly identified as taste buds in the literature.

The cupula, indispensible for the function of a mechanoreceptor, is well-formed. Methylene blue staining in living fish show them to be long rhomboid, cup-shaped structures of ca. $100 \mu \mathrm{m}$ or longer (Fig. 3). Scanning electron micrographs show the characteristic oval containing sense and supporting cells on which the cupula sits and the typical pattern for the directional sensitivity of the kinocilia and stereocilia of the sense cells. The clearly distinguishable free neuromasts on the abocular side, which can be seen with the naked eye on large fish, have a diameter of ca. 50 to
$130 \mu \mathrm{m}$. In larvae, all epidermal bud-like structures recognizable in histological cross-section develop as neuromasts. In young larvae, they are symmetrically located in small numbers; however, later during larval development they multiply considerably in the region which becomes the lateral canal. Finally, the free neuromasts organize into pattern of squares, triangles or in rows (Fig. 2). Density and distribution pattern of the neuromasts on the abocular side are illustrated in Fig. 2. On the ocular side of the body rows of free neuromasts can be observed.

Characteristic for all members of the sole family is the high density of papillae located on the abocular side of the head. The papillae, consisting of epidermis and cutis, are often concentrated in groups and are joined at their base. They reach a length of about $100 \mu \mathrm{m}$ in larvae and up to $3 \mathrm{~mm}$ in adults. They are therefore longer than the neuromast cupula. As the papillae are arranged to the right and left of each of the neuromasts, a formation emerges (Fig. 2). Electron microscopic examination shows that the papillae form an arch on each side of the neuromasts, square to the
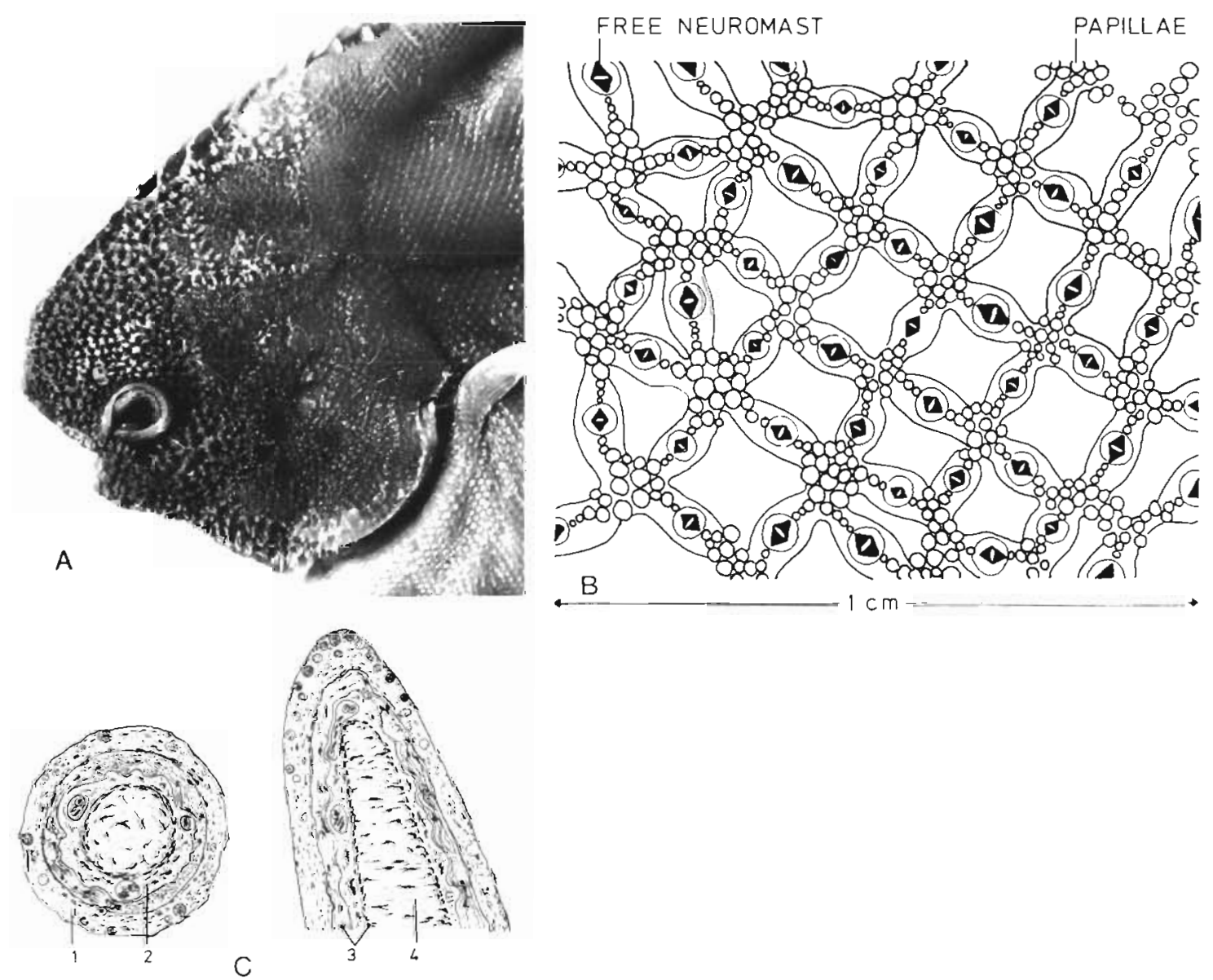

Fig. 2. Solea vulgaris. Free neuromasts and papillae on the abocular side (A \& B); C-transversal and longitudinal sections of papillae 1 - epidermis with mucous cells; 2 - loose vesicular tissue with capillary blood vessels and pigment cells; 3 - dense fibrous connective tissue; 4 - fibrous connective tissue 
main stimulus direction of the sense organs. The rhomboid cell mantle lies diagonal to the direction of the flow, whereas the sensory cells-oval lies parallel to it: this organisation is identical to the one behind the other' arrangement of the kinocilia and stereocilia which determines the characteristic direction of the neuromast ( Fig. 3).

There is no question that the density of the papillae represents significant protection for the neuromast cupula. In addition, the papillae might, through their arrangement, strengthen the directional sensitivity of the neuromasts.

The histological construction of the papillae is simple and uniform (Fig. 2 C). A central axis consisting of vesicular connective tissue is surrounded by a thin internal cylinder of dense connective tissue (with large
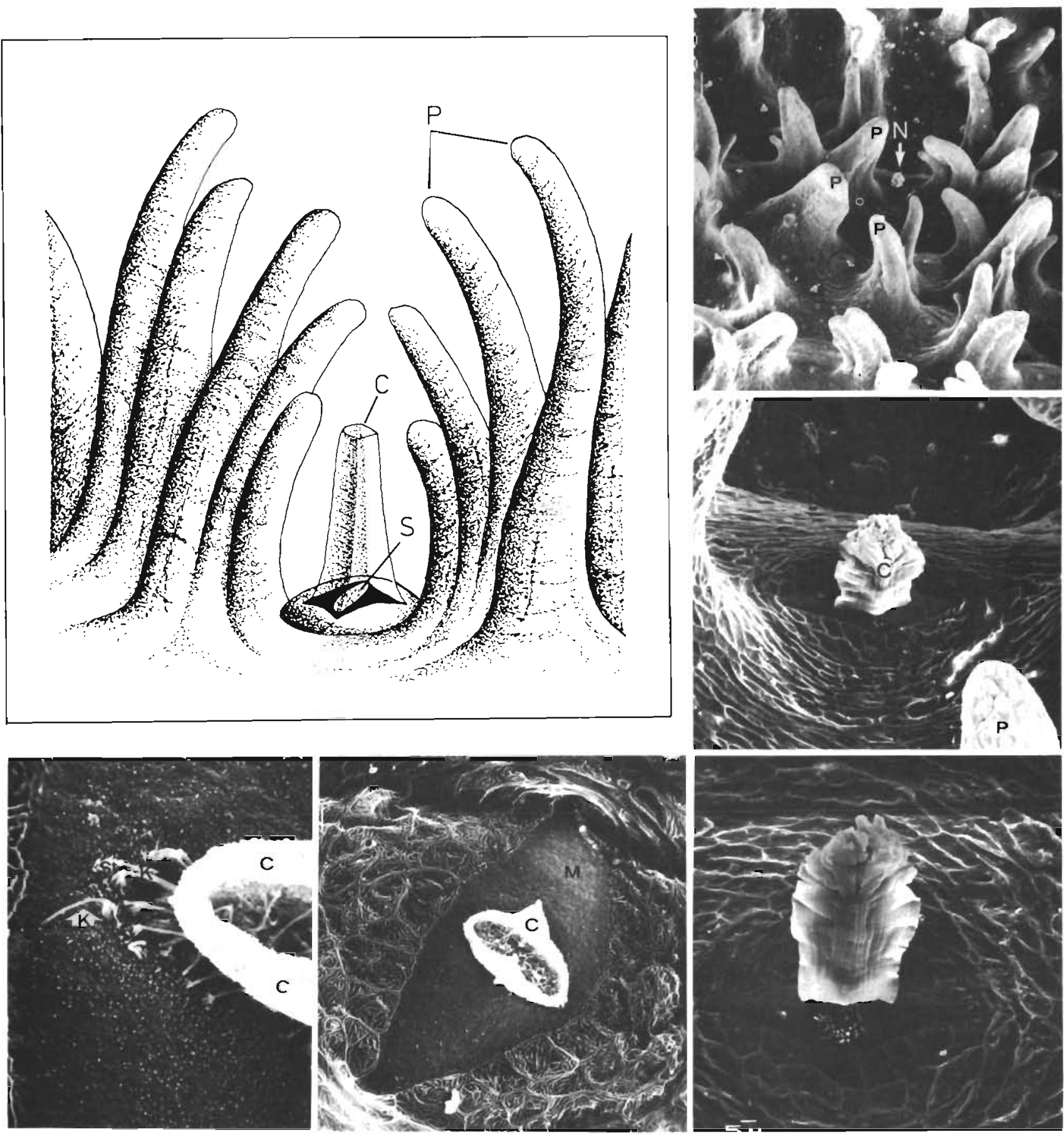

Fig. 3. Solea vulgaris. Free neuromast and papillae on abocular side. C: cupula; P: papillae; S: sensory epithelium; N: neuromast; M: mantle cells; St: stereocilia; $\mathrm{K}$ : kinocilia 
spindle-shaped nuclei) and a thick external, dense fibrillar cylinder. Between these fibrillar tissue layers and inside the loose tissue there is a well-developed capillary and lacunae system (Tirelli, 1938). The epidermis around the external dense tissue is complete and contains a large number of mucous cells. EM micrographs indicate that the epidermis exhibits the typical relief pattern of the surface epithelium.

Both the light optic examination of the cross and longitudinal sections and examinations of semi- and ultrathin sections reveal that papillae do not have sensory buds. (This fact has been repeatedly claimed or assumed in the literature but cannot be proved here.) Additionally, the existence of free nerve endings either near to or in the papillae epidermis cannot be confirmed.

\section{Gustatory organ}

Taste buds are found in the oral cavity only. They are present from the inner edge of the lips down to the pharynx, as in the turbot (Scophthalmus maximus) (Mackie and Adron, 1978). Their density varies from one area to another. In general, however, the density increases from the lips (just in front of the first row of teeth) towards the pharynx where the taste buds are found at their highest density (in a sole of about $8 \mathrm{~cm}$ length, 150 to 200 fungiform papillae were counted per $\mathrm{mm}^{2}$ ). In a specimen treated with chromium acid for 20 min the pharynx looks like a carpet of small fungiform papillae on which sensory cells associated with mucous cells are located (Fig. 4). The gill arches oppo- site the pharynx are also populated by taste buds, although not so densely. The external arch has fewer buds, the internal more. Whilst on the palate the buds are arranged in rows (Fig. 4A) there is no recognizable pattern on the tongue and other regions of the oral cavity.

\section{Olfactory organ}

The original symmetry of the olfactory organ remains essentially the same. On the abocular side, the outlet, hidden between the papillae, is situated far away from the muscular inlet which has a spiral fold. On the ocular side, the tubular nostrils are closer together and lie in a narrow angle between the eye and the oral fissure. The opening on both sides leads into a spacious but shallow nasal cavity; this is occupied by a long oval rosette of lamellae covered with the olfactory epithelium. Both nasal cavities are connected with one another by accessory sacs directly above the roof of the palate. The middle accessory sac extends caudally towards the pharynx region (Fig. 5).

Nasal sacs on either side differ in size and number of lamellae. The sac on the abocular side is smaller and contains fewer lamellae. The point most worthy of record is the fact that since the total number of lamellae increases with the growth of the fish, the relative difference between the number of lamellae on the 2 sides also increases. The nasal sac of the abocular side contains about $20 \%$ fewer lamellae than that of the ocular side.
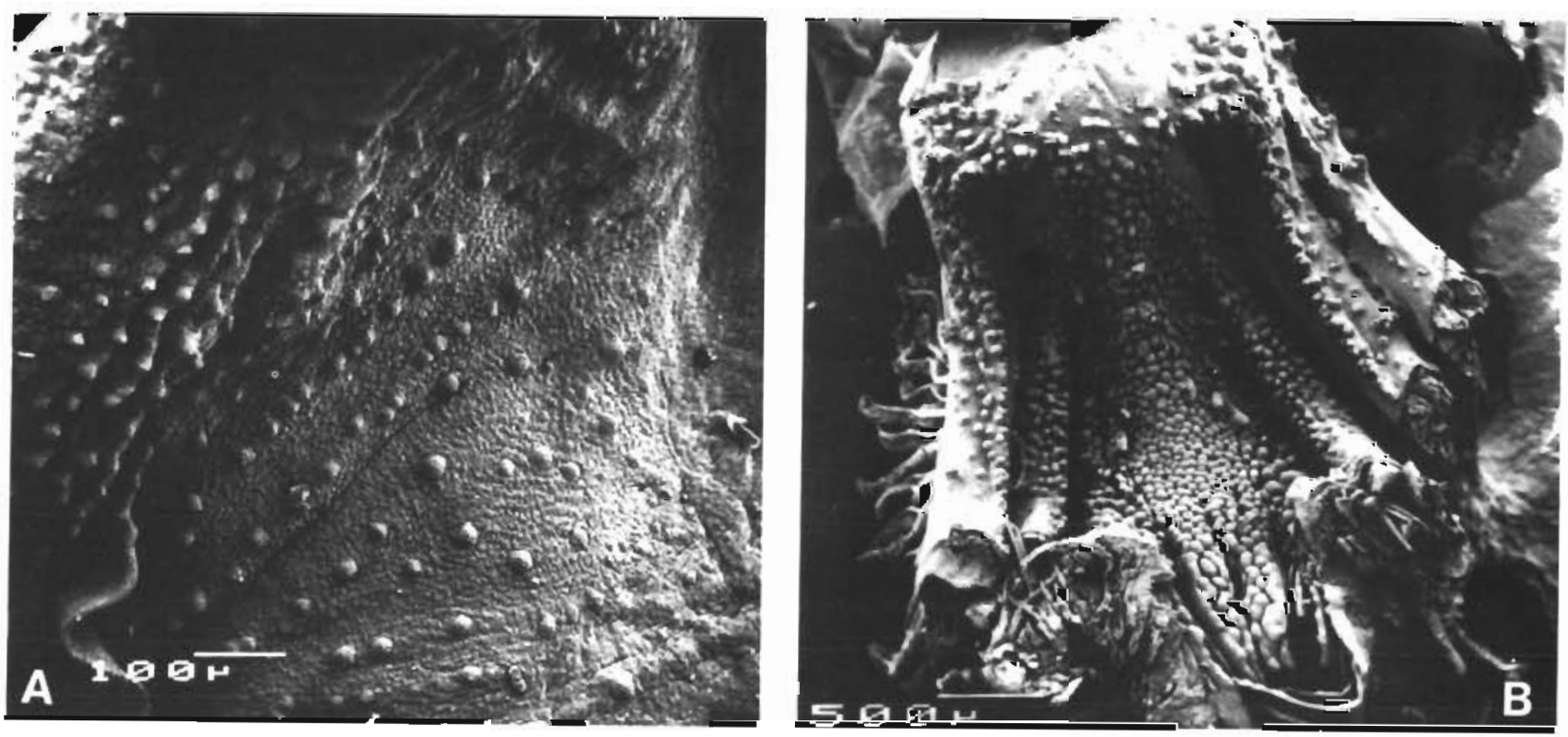

Fig. 4. Solea vulgaris. (A) Taste buds on palate. (B) Gill arches showing fungiform papillae which contain taste buds 


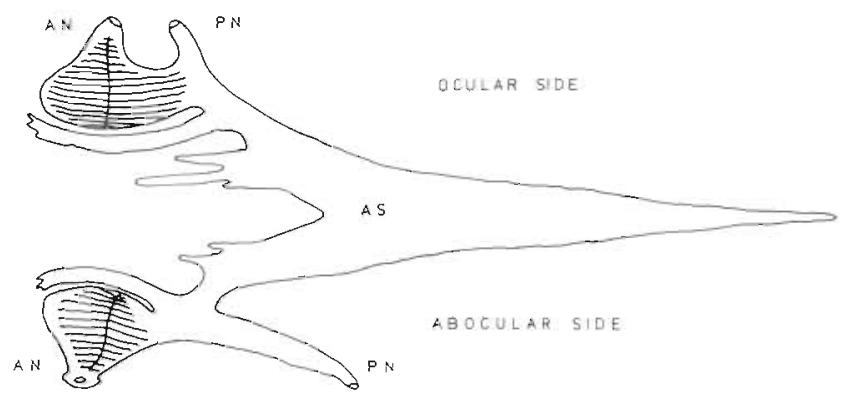

Fig. 5. Solea vulgaris. Nasal organ, drawn according to serial sections. Nasal chambers, lamellae, anterior (AN) and posterior (PN) nostril and accessory sacs (AS). View from dorsal side

\section{DISCUSSION: Significance of chemo- and mechanoreceptors for feeding behaviour}

Several authors (de Groot, 1971; Bromley, 1977; Mackie et al., 1979; Bayer et al., 1980) relate the papillae on the abocular side of the sole directly to its feeding behaviour. These papillae are described as 'sensory papillae'; some authors have even reported that taste buds occur on or between these papillae. In the present study, neither the defined 'sensory papillae' nor the existence of taste buds outside the oral cavity could be confirmed. No indications were found to prove that the papillae have a sensory function. Moreover, the formation of the papillae around the neuromast gives the impression that their purpose is to protect the free neuromast from being damaged rather than to act as sensory organs. These neuromasts are still mistaken for taste buds in the literature. The description repeated in the literature, where the sole reacts to nutrients even before ingestion by means of the gustatory organ, can neither be proved nor rejected here. Without doubt, the sole reacts at a distance to nutrients using its olfactory organ; however, it can equally well react gustatorily when water enters its mouth while breathing, thus stimulating the taste buds. (This means that there is no need to ingest the food for gustatory stimulation.) Finally, the neuromasts, carrying a thin jelly-like cupula, may also be in a position to detect certain ions (Katsuki and Yanagisawa, 1982) or even taste.

De Groot (1971) investigated the relationship between sense organs of the sole and its feeding behaviour. He found that blocking the lower anterior and posterior nostrils made hardly any difference to the feeding behaviour. But with the upper anterior and posterior nostrils blocked, the fish could not perceive their food. On the other hand, sole with their eyes removed were still capable of finding their prey (in these experiments objects imitating prey were moved gently at a distance of $20 \mathrm{~cm}$ from the fish and the reaction of the fish was noted). Of all flatfish investigated the sole was the one to react most positively to the movement of artificial prey as well as to water movement only. The latter definitely affected nothing but the mechanoreceptors.

Bayer et al. (1980) found that fish resumed normal feeding behaviour after the total removal of the nostril on the blind side. Bromley (1977) reports that sole, after tasting the food with their 'sensory papillae', still continues to savour and taste the food in the mouth before finally swallowing or rejecting it. The present study reveals that the olfactory organ on the abocular side contains less lamellae than that on the ocular side. This is in accordance with Holl's (1965) report. All these findings are surprising since it is still generally accepted that the sole, a typical benthic fish, detects food primarily by chemosensory mechanisms. It seems that mechanoreceptors are obviously involved much more in the detection of moving prey than has been noted in the literature up to now. They are probably indeed indispensable to the feeding behaviour of the sole. Appelbaum et al. (1983) found that the number of sensory buds on the head of sole larvae increases rapidly during larval development; the closer the larvae is to the end of metamorphosis the more it is able to detect live organisms in darkness.

To summarize, the present study elucidates the significance of neuromasts, present in sole in large numbers mainly on the abocular side, for the detection of food.

The free neuromasts, together with the canal system, obviously form an effective alarm system which alerts the fish to moving organisms and so enables it to detect and locate their position, e.g. the respiration movement of tube-dwelling worms (polychaetes) and of molluscs, both principal sources of food for the sole. This does not exclude the importance of the chemosensory mechanisms involved in the sole's feeding behaviour.

The economic importance of the sole has given rise to many experiments in the last decade with the aim of commercial cultivation. However, there are stil difficulties with the weaning of larval and postmetamorphosed fish from live food to a pelleted diet. In this respect, when planning further feeding experiments, the possibility of stimulating the mechanoreceptors (i.e. in the feeding technique) should be considered. Used in conjunction with food attractants, this should make the fish significantly more willing to ingest artificial diets.

Acknowledgements. The authors are grateful to Frau Dr. E. Wahl, Biologische Anstalt Helgoland, for providing sole eggs and fish. Our thanks are due also to Dr. D. Keyser and Miss E. Ganss for their assistance in the use of the electron microscope. The loan of the SEM by the Deutsche Forschungs- 
Gemeinschaft to the Zoological Institute of Hamburg is appreciated

\section{LITERATURE CITED}

Appelbaum, S., Adron, J. W., George, S. G., Mackie, A. M., Pirie, B. J. S. (1983). On the development of the olfactory and the gustatory organs of the Dover Sole, Solea solea, during metamorphosis. J. mar. biol. Ass. U. K. 63: 97-108

Bayer, R. C., Adron, J. W., Mackie, A. M., Pirie, B. J. S. (1980). Mechanisms of food detection and feeding behavior in the Dover Sole (Solea solea). Fedn Proc. Fedn Am. socs exp. Biol. 39 (3): Abstract 1227

Bromley, P. J. (1977). Methods of weaning juvenile hatchery reared Sole (Solea solea [L.]) from live food to prepared diets. Aquaculture 12: 337-347

Burne, R. R. (1909). The anatomy of the olfactory organ of the teleostean fishes. Proc. Zool. Soc. Lond. 79: 610-633

Butler, G. W. (1895). Report on the spawning of the common sole (Solea vulgaris) in the aquarium of the Marine Biological Association's Laboratory at Plymouth, during April and May, 1895. J. mar. biol. Ass. U. K. 63: 3-9

Chabanaud, P. (1927). L'organe nasal de Solea vulgaris. C. r. hebd. Séanc. Acac. Sci., Paris 185: 1306-1307

Creutzberg, F. (1958). Use of tidal streams by migrating elvers Anguilla vulgaris Turt. Nature, Lond. 181

Cunningham, J. T. (1890). North Sea investigations. J. mar. biol. Ass. U. K. 63: 10-47

Evans, M. H. (1937). A comparative study of the brains in Pleuronectidae. Proc, R. Soc. (Series B) 122: 308-343

Flüchter, J. (1966). Spawning, first feeding and larval behaviour of the North Sea sole. Cons. perm. int. Explor. Mer C.M. C: 3 (mimeo)

Girin, M., Metailler, R., Nedelec, J. (1977). Accoutumance de Jeunes Soles (Solea solea) à différents aliments inertes après achèvement de la métamorphose. I. C. E. S. 3rd Mariculture Working Group. Hamburg, 16 pp., mimeographed

Groot, S. J., de (1969). Digestive system and sensorial factors in relation to the feeding behaviour of flatfish (Pleuronectiformes). J. Cons. int. Explor. Mer 32: 385-394

Groot, S. J., de (1971). On the inter-relationships between morphology of the alimentary tract, food and feeding behaviour in flatfishes (Pisces: Pleuronectiformes). Neth. J. Sea Res. 5: 121:196

Groot, S. J., de, Corten, A. A. H. M. (1967). Occlusion of smell perception in the common sole, Solea solea (L.). Cons. perm. int. Explor. Mer C. M./B: 3

Heape, W (1887). Notes on the fishing industry of Plymouth. J. mar. biol. Ass. U. K. (old series) 1: 45-95

Holl, A. (1965). Vergleichende morphologische und histologische Untersuchungen am Geruchsorgan der Knochenfische, Z. Morph. Okol. Tiere 54: 707-782

Katsuki, Y., Yanagisawa, K. (1982). Chemoreception in the lateral line organ. In: Chemoreception in fishes. Elsevier, Amsterdam, Oxford, p. 227-243

Kirk, R. G. (1973). Adaptation of the young common sole (Solea solea L.) to diets prepared from the mussel, Mytilus edulis, L., and the slipper limpet, Crepidula for nicata. Coun. Meet. int. Coun. Explor. Sea C.M.-I.C.E.S./E: 17 (mimeo)

Mackie, A. M., Mitchell, A. I. (1982). Further studies on the chemical control of feeding behaviour in the Dover sole, Solea solea. Comp. Biochem. Physiol. 73 A: 89-93

Mackie, A. M., Adron, J. W., Grant, P. T. (1980). Chemical nature of feeding stimulants for the juvenile Dover sole, Solea solea (L.). J. Fish Biol. 16: 701-708

Mackie, A. M., Adron, J. W. (1978). Identification of inosine and inosine 5 -monophosphate as the gustatory feeding stimulants for the Turbot, Scophthalmus maximus. Comp. Biochem. Physiol. 60A: 79-83

Mackie, A. M. 1982. Palatability-researchers look for the key actors. Fish Fmr 5: 3 (21)

Raffaele, F. (1886). Papille e organi di senso cutanei nei Pleuronettidi del gen. Solea. Nota preliminare: Riv. ital. Sci. nat. $2: 1-2$

Romeis, B. (1968). Mikroskopische Technik. R. Oldenbourg, München, Wien

Rosenthal, H. (1966). Beobachtungen über das Verhalten der Seezungenbrut. Helgoländer wiss. Meeresunters. 13: 213-228

Shelbourne, J. E. (1975). Marine fish cultivation: pioneering studies on the culture of the larvae of the plaice (Pleuronectes platessa L.) and the sole (Solea solea L.). Fishery Invest., Lond. (Ser. 2) 27 (3): 1-29

Schemmel, Ch. (1974). Genetische Untersuchungen zur Evolution des Geschmacksapparates bei cavemicolen Fischen. Z. zool. Syst. Evolutionsforsch. 12 (3): 196-215

Tirelli, M. (1936). I bottoni di senso e le papille del lato nadirale dei Soleini. Mem. R. Comitato Talassografico Italiano, Mem. 232

Tirelli, M. (1938). Osservazioni sulla sistema di bottoni di senso e di papille del lato cieco del capo dei Soleidi, con particolare riguardo alla struttura delle papille. Biol. Zbl. 58: $333-340$ 